Journal of Social and Development Sciences

Vol. 3, No. 1, pp. 16-23, Jan 2012 (ISSN 2221-1152)

\title{
Attitudes and Awareness towards Environmental Management and its Impact on Environmental Management Practices (EMPs) of SMEs in Sri Lanka
}

\author{
*Sudath Weerasiri, Zhang Zhengang \\ South China University of Technology, Guangzhou, China \\ *sudathweerasiri@hotmail.com
}

\begin{abstract}
The main objective of this paper was to investigate whether there is an association amongst SMEs' attitudes, awareness on environmental issues and their environmental management practices. A questionnaire-based survey was chosen to obtain the information on attitudes, awareness and environmental management practices of SMEs. The questionnaire was developed to find out SMEs' current environmental management practices as well as their attitudes and awareness on environmental issues. The associations amongst attitudes, awareness and environmental practices for waste, energy, and the environment were investigated by calculating correlation coefficient. These analyses revealed that there is no significant association between attitudes and awareness or attitudes and environmental management practices. Attitudes appear to be remaining positive even where awareness is limited. Managers/owners who expressed rather more positive attitudes appear no more likely introduce environmental management practices for their organizations than managers/owners with less or negative attitude.
\end{abstract}

Key words: Environmental Management; Environmental Management Practices; Attitudes; Awareness; SMEs

\section{Introduction}

The Small and Medium sized Enterprises (SMEs) are identified as one of the leading group of economic activities globally and support a substantial part of the economic activities in the Asia Pacific region. The number of SMEs in each country accounts for more than $60 \%$ of their domestic industrial production. In Thailand, SMEs make up $99 \%$ of the total business enterprises and the number is increasing with3.6percentage for small-sized and $9.8 \%$ for medium - sized of annual growth rate. Their contribution to the Gross Domestic Production (GDP) amounted to 40\%. Approximately 4.5 million workers in Vietnam are employed by SMEs. In India, 50\% of the country's total exports are manufactured by SMEs (http//www.iges). In Sri Lanka SMEs constitute $80-90 \%$ of total establishments and $20 \%$ of industrial value added. It accounts for $70 \%$ of employment generated in the business sector (Cooray and Silva, 2008). With this strong influence on economic and social matters, environmental impacts attributes to the SMEs are significant, not only the magnitude but also diversity. The environmental impacts of small firms are not known either at national or regional levels. It is widely quoted that, as a sector, SMEs could contribute up to $70 \%$ of all industrial pollution (Hillary, 1995). The influential may be more in the Asia - Pacific than any other region in the world because of the rapid economic growth of the region today. In spite of the fact, however, the measures undertaken so far have not yielded impressive results. Especially when compared to those large companies. Thus, the environmental performance of SMEs remains week in many parts of the region and it is believed that the environmental damage caused by SMEs will grow unless innovative strategies are devised. On the hand, SMEs are in the region now facing the challenge of competitive market. However, many of them struggling with survival strategies. Thus making issues of competitiveness and marketing top priorities, while environmental issues are far behind.

In Sri Lanka, SMEs consist of both manufacturing and service sector enterprises in a wide spectrum of industry disciplines. In addition to the standalone enterprise nature, these SMEs play an important role in supply chain links to the large industry/service sector too. The national strategy of Government of Sri Lanka has clearly recognized the importance of SME sector development. Therefore number of programs aimed at making SMEs more competitive by applying modern technology to improve production processes and make SMEs more efficient. However SME sector in Sri Lanka is typically associated with high adverse environmental impacts due to the sheer number of units, and some of them are dominant in resource and 
emission intensive trades such as metal finishing, leather tanning, dry cleaning, printing and dyeing, brewing, food processing, fish farming / processing, automobile servicing and repairing, metal fabrication, textile manufacturing, paper and pulp, rubber and rubber products, wood and wood products, chemical production etc. Moreover, their compliance status is less than desirable, resulting in adverse impacts on public life, health and the environment. Some of the defining characteristics of the SME sector which contribute to poor levels of environmental control in operations are,

- Poor business planning without following the sustainable development framework due to lack of guidance on same;

- Lack of understanding of environment, public health and safety issues;

- Limited awareness on legal and regulatory obligations;

- Poor environment practices due to non- regularized labor practices;

- Non-adoption of cleaner technologies or use of expensive pollution control equipment due to low economies of scale.

- Poor compliance monitoring by the responsible agencies (SMEDeF, 2010)

According to the State of the Environment Sri Lanka (2005) "most of the technologies used by small and medium sized enterprises are outdated or inefficient and hence to tend to consume high amount of water and generate large pollutant loads." Within this context, it is very important to studying environmental management practices of SMEs since they are playing a vital part of the enterprise society. Owing their labor-intensive operations, they provide substantial portion of individuals and have contributed largely towards economic development in the nation. In other words, SMEs represent two out of three main elements (economical and social) in the sustainable development. Hence, with a better understanding about the attitudes and awareness towards environmental management of SMEs, we can propose an effective recommendation to encourage them for integrating an effective environmental management practices for their organizations. However, SME sector and their environmental issues are comparatively under researched or ignored by the academia. The SMEs research has in recent years come in for some criticism for its lack of theoretical rigor and conceptual development (Goss, 1991). The business- environment literature has in the main neglected SMEs, instead focusing its attention on the large firms (Smith, 1997).

However, the emerging literature on SMEs and the environment has also been accused of insufficient analytical inquiry, relying too heavily on anecdote (Gladwin, 1993; Geiser and Crul, 1996).Therefore a need to direct a conceptual emphasis upon investigations of the relationship between small firms and the environment. The environmental solutions designed for large firms cannot necessarily be applied to SMEs. It has been noted SMEs often differ from larger firms in their management style, organizational structure and the characteristics of the owners/ managers (Dandridge, 1979). Further, they are often resource poor, lack of assessing finance and labor and presenting the problem of finding the necessary time to manage environmental matters (Welsh and white, 1981). SMEs need their own unique answers to and understanding of the difficult environmental problems, they face. The indications to date suggest there is a need for further research of the relationship between SMEs and the environment. In Sri Lanka, significant number of writings aimed at SMEs but much of these writings are being spent the outlining the economic, marketing, liability, legal and employment aspects. The SMEs and the environmental issues have not been sufficiently investigated. Therefore, as an academia we have yet to develop an effective methodology to analyze these issues. This study tries to fill this deficit by analyzing the environmental management practices of SMEs in Sri Lanka. Accordingly, the main purpose of this study is to analyze the attitudes and awareness of environmental management of SMEs and its impact on their environmental management Practices (EMPs).

\section{Review of Literature}

A sustainable business should have its unique position to develop and achieve sustainable production and sustainable consumption at the same time. A responsible and sustainable system of environmental management should start with pollution prevention then expand into control and environmental design (Chavan, 2005). The ability of organizations to manage their environmental performance is emerging as a strategic issue for many companies worldwide. This is because the environment is now regarded as an asset 
to be valued. On the other hand, managers today are not only expected to reduce lead times, improve quality, reduce cost and enhance flexibility, they are also expected to become more environmentally responsible (Monatabon et al., 2000). Therefore, the significant impact of SMEs in terms of input and output requirements and the size of workforce they employ deserve special attention, and engaging them in environmental improvement is regarded as a vital part of sustainable development (Hillary, 2004). The environmental management is "the system that anticipates and avoids or solves environmental and resource conversation problems (Thompson, 2002)". In 1970s and 1980s, the concept of environmental management was largely technocratic and end of pipe (Barrow, 2005). At the end of 1980s, environmental management began to seen, as cost reduction and an institutionalized organizational task, and being green and clean became a popular catchphrase for advertisement products. However, in 1990s with the increased of stakeholders' pressure on environment, organizations recognized the environmental impacts associated with their operation through the introduction of comprehensive environmental management systems.

In the last twenty years, environmental management has shifted from being subject to "Command and control" to self-regulation and accept public accountability and consultation (Martin, 2002). Environmental management is still undergoing rapid change, but the goal remains the same to ensure sustainable development. Even though there have been significant developments in environmental management in the last decades, the implementation of environmental management predominantly adopted by large companies (Merrit,1998).However, SMEs will also have to demonstrate their contribution to zero negative impact on the environment because of more rigid regulations and supply chain pressure(Welford and Gouldson, 1993). Further, the competitive advantage will be achieved by integrating environmental considerations into business strategy and daily operations, which may lead to new environmentally friendly products and service. Steger (2000) viewed that a systematic environmental management leads to the discovery and exploitation of new 'win - win' potential. Empirical study also shows that a comprehensive environmental management can help organizations reduce environmental incidents and civil liabilities, increase efficiency by reducing waste and encouraging recycling, improve environmental awareness among employees and meet stakeholder satisfaction (Welford and Gouldson, 1993).

Stakeholder Theory: Stakeholder theory or framework identifies a corporation as a "system of primary stakeholders". According to the theory, a corporation's survival and failure depends on whether the corporation satisfies the expectations of its stakeholders. It is intuitively appealing that corporations have their stakeholders influencing ultimate success in the market. Not surprisingly, stakeholder theory has become "a popular heuristic for describing the management environment" (Mitchell et al., 1997). In addition, the idea of a corporation surrounded by stakeholders is commonplace in the management literature (Donaldson and Preston, 1995). This study highlights the normative sources of external pressures advocated by stakeholder theory. The theory argues that the responsibility of managers in the stakeholder management context is not limited to shareholders, but includes various Stakeholders (Clarkson, 1995). Further, the stakeholder approach emphasizes the notion that firms have responsibilities for constituent groups in society other than stakeholders and obligation not clearly stipulated in existing laws and regulations (Jones, 1980). The sacrifices of stakeholders' interest due to economic interest of shareholders are not justified any more.

SMEs' Attitudes and Environmental Issues: The barriers to the implementation of environmental initiatives in small and medium sized enterprises have been classified by Hillary (2004) as internal barriers and external barriers. Although internal and external barriers exist, the internal barriers are the greatest impediment to EMS implementation (DeCanio, 1998; Hillary, 2004). Of these, many are barriers related to environmental attitudes. However, many studies suggest that the lack of movement towards greater adoption of environmental practices and initiatives in business is not primarily due to a lack of positive environmental attitudes in business (Meritt, 1998; Tilley, 1999; Schaper, 2002).Although positive environmental attitudes have been found to be an important factor in the introduction of environmental initiatives in businesses (Naffziger et al., 2003), it does not appear that this criteria is sufficient to produce behaviors consistent with those attitudes. To illustrate this issue, in a 2004 study of UK SMEs, Simpson et al. (2004) reported that 77\% of the responding companies thought that environmental issues were business issues. In spite of this, SMEs generally did not participate in waste reduction strategies even when faced with increasing waste disposal costs. A number of studies have identified this gap between the environmental attitudes of owners and managers towards environmental issues and the behaviors that were performed (Meritt, 1998; Tilley, 1999; 
Petts et al., 1999; Williams et al., 2000; Schaper 2002). In other behavioral studies, it has been shown that pro-environmental attitudes are poor predictors for pro-environmental behavior (Biel et al., 2005; Biel and Dahlstrand, 2005). A study of SME environmental attitudes and behaviors by Tilley (1999) reinforces these findings as it reports that SMEs presently have insufficient motivation to move from their pro-environmental attitudes to behavior. The same study also highlights evidence that these attitudes however have the potential to become behaviors.

SMEs' Awareness and Environmental Issues: Many SMEs around the world have little knowledge about environmental management and do not understand the concept of environmental management. Therefore, it is very difficult SMEs to see clear link between EMS implementation and the benefits. On the other hand, management systems in SMEs generally focus on every day business and tend to be immediate, responding to critical incidence situation management. Thus, long-term intangible environmental benefits will receive low priority. Therefore, as Hillary (1999) pointed out, negative corporate attitudes towards EMSs and intransigent company culture would impede EMS implementation. SMEs also have lack of awareness of environmental legislation. The complexities of legislation make further confuse matters and deter business from fully grasping the implications (Stuart, 2000). Many SMEs think that their impact on the environment is minimal and therefore do not realize the extent to which environmental legislation affect them (Stuart, 2000). SMEs do not take time to understand the relevant legislation and how environmental issues affect them. As a result, many SME businesses are reactive rather than proactive when dealing with the environmental issues. Howes (1997) argued that there seems to be lack of awareness and lack of information on waste minimization technologies. Smith (1997) also recognized the importance of raising the awareness of environmental issues in the SME sector. However, it is important to notice that SMEs owner managers tend to prefer informal communication and control structures (Bosworth, D., Jocabs, C., 1989). Bianchi and Noci (1998) argued that the introduction of a pro - active 'green 'strategy within SMEs is problematic for two major reasons. First, it requires resources and skills that, in many cases, are not available in SMEs. Second, at present it can hardly be justified from an economic and a competitive viewpoint, since management has to invest significant financial resources (such as new equipment, training, creation of new skills etc), without any certain returns in the short term. It must be remembered that most customers do not yet wish to pay a premium price for environmentally friendly products so it is very difficult for SMEs to publicize their effort in the environmental field.

\section{Methodology}

Sample: The Western province of Sri Lanka was selected for the survey since more than $50 \%$ of SMEs are located in Western province (Dasanayake, 2009). Based on World bank definition, the enterprises which employed 1-49 employees are identified as small sized enterprises and the enterprises employed 50 -99 employees are identified as medium sized enterprises. Altogether 100 firms randomly selected for the survey with the help of data provided by Industrial Development Bank of Sri Lanka (IDB, 2011). Table 1 shows a breakdown of respondents according to the size of the company.

Table 1: Size profile of the respondents

\begin{tabular}{llcc}
\hline Category & Employees & Respondents & Percentage \\
\hline Small & $1-49$ & 68 & 68 \\
Medium & $50-99$ & 32 & 32 \\
Total & & 100 & 100 \\
\hline
\end{tabular}

Source: Survey Data 2011

Collection of Data: A structured questionnaire was used to collect the data and it was mainly focused to collect the information on what firms actually doing in relation to environmental issues (environmental practices), what managers' belief regarding environmental issues and environmental protection (attitude) and their knowledge (awareness) of environmental management. The key intention was to study that is there any possible relationship amongst attitudes, awareness and environmental practices. The questionnaire 
was segmented into three main clusters namely energy, waste and the environment. The questions of each segment focused on attitudes, awareness and practices. Further, the questions included to find out more general information about the firms such as company size, type of business, number of employees etc. The questionnaire constructed with some open-ended questions pertained to barriers to implement environmental management practices for SMEs in Sri Lanka.

Constructing of scales: The questionnaire was structured to permit the construction of a series of scales. The reason was to classify the questions in the questionnaire such as:

- By type (attitude, awareness and practices)

- $\quad$ By subject (energy, waste, environment)

Table 2 shows some of the examples in each of the category to illustrate the way in which these terms are used. This classification system did permit respondent to rate points according to their opinions. By summing these points, it was assigned an overall score on each of the nine scales.

\section{Table 2: Classification of questions according to type and subject for scale construction}

\begin{tabular}{|c|c|c|}
\hline $\begin{array}{l}\text { Type } \\
\text { Attitudes }\end{array}$ & Subject & Sample questions \\
\hline \multirow[t]{3}{*}{ Attitudes } & Energy & $\begin{array}{l}\text { 'Energy efficiency is a key element in cost control' Do you (a) } \\
\text { agree strongly (b) agree (c) neutral (d) disagree (e) disagree } \\
\text { strongly...? }\end{array}$ \\
\hline & Waste & $\begin{array}{l}\text { 'Waste minimization is a waste of time' Do you (a) agree } \\
\text { strongly (b) agree (c) neutral } \\
\text { strongly...? }\end{array}$ \\
\hline & Environment & $\begin{array}{l}\text { 'All businesses have a responsibility to protect the } \\
\text { environment' Do you (a) agree strongly (b) agree (c) neutral } \\
\text { (d) disagree (e) disagree strongly...? }\end{array}$ \\
\hline Awareness & $\begin{array}{l}\text { Energy } \\
\text { Waste } \\
\text { Environment }\end{array}$ & $\begin{array}{l}\text { Various Likert types of questions relating to respondents } \\
\text { awareness on energy efficiency, waste minimization and the } \\
\text { environment. }\end{array}$ \\
\hline Practice & $\begin{array}{l}\text { Energy } \\
\text { Waste } \\
\text { Environment }\end{array}$ & $\begin{array}{l}\text { Various Likert types of questions relating to respondents } \\
\text { energy policy, waste practices and the firm's environmental } \\
\text { practices. }\end{array}$ \\
\hline
\end{tabular}

Analysis of data: The analysis of data was supported by coding the questionnaire; constructing scales (see Table 2) and entering data to SPSS (version 18). The necessary checks were executed at various stages to ensure the quality of data input process. After this initial process the data were ready for analysis. The purpose here was to obtain the followings:

- Summary statistics for key individual variables (Attitudes, Awareness, Practices)

- Summary statistics for scores representing awareness, attitudes and practices

- Correlation between key individual variables

\section{Results and Discussion}

Summary Statistics for attitudes, awareness and practices: According to the Table 3 respondents expressed highly positive attitudes concerning the importance of environmental issues and the responsibilities of business with regard to those issues. However, their positive attitude does not either appear to be reflected in their awareness of key information in environmental management (see Table 4) or in their environmental practices (see Table 5).

Correlations between attitudes, awareness and practices: The associations between attitudes, awareness and practices for waste, energy and the environment were investigated by calculating correlation coefficient 
(See Table 6). These calculations reveal that there is little or no significant association between attitudes and awareness or between attitudes and practices. In other words, attitudes appear to be remaining positive even where awareness is limited. Managers with rather more positive attitudes appear no more likely to introduce environmental management practices for their organizations than those with fewer attitudes. However, there is some general association between awareness (knowledge) and practice (doing); and between practices relating to energy and waste management. In other words, knowing (awareness) and doing (practice) seems to go together

Table 3: Responses in relating to questions on attitude

\begin{tabular}{lc}
\hline Responses & Percentage \\
\hline $\begin{array}{l}\text { Agreed or Strongly agreed that 'All business have a responsibility to protect the } \\
\text { environment' }\end{array}$ & 94 \\
Agreed or Strongly agreed that 'Good environmental management is an essential part of & 93 \\
business management' & 89 \\
Disagreed or Strongly disagreed that 'Energy efficiency is not important' & 92 \\
Agreed or Strongly agreed that 'Every business have a responsibility to minimize the & \\
waste they produce' & 95 \\
Agreed or Strongly agreed that 'Waste minimization is important for environmental & 95 \\
reasons' & 90 \\
\hline Disagreed or Strongly disagreed that 'Waste minimization is a waste of time' &
\end{tabular}

Table 4: Responses to questions in relating to awareness

\begin{tabular}{lc}
\hline Responses & Percentage \\
\hline Unaware of Environmental Protection License (EPL) & 46 \\
Unaware of National Environmental Act (NEA) & 83 \\
Unaware of National Environmental Authority office & 29 \\
Unaware of ISO 14001 Environmental Management System (EMS) & 67 \\
Unaware of Pollution Control and Abatement Fund (PCAF) & 84 \\
Unaware of Environmentally Friendly Solutions Fund (E-Friends) & 83 \\
\hline
\end{tabular}

Table 5: Responses to questions relating to environmental practices

\begin{tabular}{lc}
\hline Responses & Percentage \\
\hline Have written environmental policy & 10 \\
Have designated Environmental Manager & 11 \\
Have introduced some kind of environmental management system & 6 \\
Encouraged staff turn off lights when not in use & 80 \\
Have undertaken environmental audit & 11 \\
Separate waste at least two categories & 8 \\
\hline
\end{tabular}

Table 6: Correlations between attitudes, awareness and practices

\begin{tabular}{lll}
\hline Association & $\begin{array}{c}\text { Correlation } \\
\text { Coefficient }(\mathbf{r})\end{array}$ & Significance \\
\hline Waste attitude and waste awareness & $\mathrm{r}=0.2$ & 0.05 \\
Energy attitude and energy awareness & $\mathrm{r}=0.1$ & 0.071 \\
Environmental attitude and awareness & $\mathrm{r}=0.1$ & 0.087 \\
Waste practice and waste attitude & $\mathrm{r}=0.14$ & 0.587 \\
Waste practice and waste awareness & $\mathrm{r}=0.11$ & 0.431 \\
Energy practice and energy attitude & $\mathrm{r}=0.13$ & 0.330 \\
Energy practice and energy awareness & $\mathrm{r}=0.32$ & 0.010 \\
Environmental practice and attitude & $\mathrm{r}=0.06$ & 0.218 \\
Environmental practice and awareness & $\mathrm{r}=0.30$ & 0.010 \\
\hline
\end{tabular}




\begin{tabular}{lll}
\hline Waste practice and energy practice & $r=0.51$ & 0.010 \\
\hline
\end{tabular}

\section{Conclusion}

As per the holistic view, the owners/managers of SMEs in Sri Lanka have limited awareness of business issues relating to environmental management and have not adopted management practices designed to improve their environmental performance. The findings figured out on attitudes were to be considered in this context. It requires obviously less effort to express positive attitudes about environmental issues and since the nature of popular discourse on environmental issues, and it results something as naturally what managers do. This does not reflect that the 'expressed' nature of attitudes is as accurate reflection of 'actual attitudes'. As far as awareness and practices are concerned, the research concludes to provide an insight that there is a substantial gap between SMEs and the large enterprises. However SMEs should constitute some kind of attention and reasonable set of initiatives pertained to the problem in the field of environmental management whilst there is an obvious gap between SMEs and the larger enterprises in the context of managing the environmental performance.

Further research: The discussion of this paper highlights several potentially areas for further research on the SME and the environmental management. These areas include:

- This study focused only associations between attitudes, awareness and practices. It is very important to study on the associations between SMEs' stakeholders, resources and the environmental management practices.

- The sample selected for this study without concerning the different sectors of SMEs, there may be some differences that might exist different sectors and different size of SMEs

\section{References}

Barrows, C. J. (2005). Environmental Management and Development, Abingdon, Rutledge.

Bianchi, R. \& Noci, G. (1998). Greening SMEs' Competitiveness. Small Business Economics, 11, 269-281.

Biel, A., Dahlstrand, U. \& Grankvist, G. (2005). Habitual and value-guided purchase behavior. Ambio, 30, 360365.

Biel, A. \& Dahlstrand, U. (2005). Values and habits: a dual process model. In environment, information and Consumer Behavior, Cheltenham, Edward Elgar.

Bosworth, D. \& Jacobs, C. (1989). Management attitudes, behavior, and abilities as barriers to growth, in barriers to Growth in Small Firms, Rutledge, London.

Chavan, M. (2005). An appraisal of environment management systems: a competitive advantage for small businesses. Management of Environmental Quality: An International Journal, 16(5), 444-463.

Clarkson, M. B. E. (1995). A stakeholder Network for Analyzing and Evaluating Corporate Social Performance. Academy of Management Review, 20(1), 92-117.

Cooray, M. N. R. \& Silva, K. R. D. (2008). Facilitating the development of SMEs of Sri Lanka through Sustainable Consumption and Production.

Dandridge, T. C. (1979). Children are not little Grown- ups: Small Business needs its own Organizational Theory. Journal of Small Business Management, 17(2), 53-57.

Dasanayake, D. (2009). Paper presented for the special IARIW - SAIM Conference on "Measuring the Informal Economy in Developing Countries Kathmandu, Nepal, September, 22-26.

DeCanio, S. J. (1998). The efficiency paradox: bureaucratic and organizational barriers to profitable energy saving investments. Energy policy, 26(5), 441-454.

Donaldson, T. \& Preston, L. E. (1995). The stakeholder Theory of the Corporation: Concepts, Evidence, and Implications. Academy of Management Review, 20(1) 65-91.

Geiser, K. \& Crul, M. (1996). Greening of Small and Medium Sized Firms: Government, Industry and NGOs initiatives, the greening of Industry Resource Guide and Bibliography, Island, Washington DC.

Gladwin, T. N. (1993). The Meaning of Greening: A Plea for Organizational Theory, Washington D.C., Island Press.

Goss, D. (1991). Small Business and Society, Rout ledge, London.

Hillary, R. (1998). An Assess of the Implementation status of Council Regulation (No 1836/93) Eco Management and Audit Scheme (EMAS) in the European Union Member Status (AIMS-EMAS, Imperial College, London, UK http://europa.eu.int/comm/emas. 
Hillary, R. (1995). Small firms and the environment-a groundwork status report, Birmingham: Groundwork.

Hillary, R. (1999). Evaluation of Study Reports on the Barriers, Opportunities and Drivers for Small and Medium Sized Enterprises in the Adoption of Environmental Management Systems, Department of Trade and Industry Environment Directorate.

Hillary, R. (2004). Environmental management systems and the smaller enterprise. Journal of Cleaner Production 12, 561-569.

Howes, S. (1997). Integrated Pollution Control, Clean and Competitive? In motivating Environmental Performance in Industry, Earth scan, London. Http://.ijes.or.jp/APEIS/RSIPO/spo/pdf/ overall/3.5.2 sme.pdf

Industrial Development Board. (2011). Centre for Industrial Information Technology Service, (CITIS), Moratuwa, Sri Lanka.

Jones, T. M. (1980). Corporate Social Responsibility Revisited, Redefined. California Management Review, 22(2), 59-67.

Martin, S. (2002). Professionals and Sustainability. Journal of the Institution of Environmental Science, 11(3), 6-7.

Merritt, J. Q. (1998). EM into EMS won't go? Attitudes, awareness and practices in the London, Borough of Croydon. Business Strategy and the Environment, 7, 90-100.

Mitchell, R. K., Agle, B. R. \& Wood, D. J. (1997). Toward a Theory of Stakeholder Identification and Salience: Defining the Principle of whom and What Really Counts. Academy of Management Review, 22(4), 853886.

Montabon, F., Melnyk, S. A., Sroufe, R. \& Calantone, R. J. (2000). ISO 14000: assessing its perceived impact on corporate performance. Journal of Supply Chain Management, 36, 4-16.

Naffziger, D. W., Ahmed, N. U. \& Montagno, R. V. (2003). Perceptions of environmental consciousness in U.S. small businesses: An empirical study. Advanced Management Journal, 68(2).

Petts, J., Herd, A., Gerrard, S. \& Horne, C. (1999). The climate and culture of environmental compliance within SMEs. Business Strategy and the Environment, 8(1), 14-31.

Schaper, M. (2002). Small firms and environmental management: predictors of green purchasingin Western Australian pharmacies. International Small Business Journal, 20(3), 235-251.

Simpson, M., Taylor, N. \& Barker, K. (2004). Environmental responsibility in SMEs: does it deliver competitive advantage? Business Strategy and the Environment, 13, 156-171.

SMEDeF. (2010). Crisis Response SME Development Facility, Ministry of Finance and Planning.

Smith, M. (1997). Stimulating environmental action in Small to Medium-sized Enterprises, Environmental Management Systems and Cleaner Production, Wiley: Chic ester.

State of the Environment Sri Lanka. (2008). United Nations Environment program, Regional Resources Centre for Asia and the Pacific (UNEP-RRC. AP).

Steager, U. (2000). Environmental Management Systems: Empirical evidence and further perspectives. European Management Journal, 18, 23-27.

Stuart, R. (2000). Environmental Management Systems in the 21 ${ }^{\text {st }}$ Century. Chemical Health and Safety, 7(6), 23-25.

Thompson, D. (2002). Tools for Environmental Management: A Practical Introduction and Guide, Gabriola Island, BC: New Society Publishers.

Tilley, F. (1999). The gap between the environmental attitudes and the environmental behavior of small firms. Business Strategy and the Environment, 8, 238-248.

Welford, R. \& Gouldson, A. (1993). Environmental Management \& Business Strategy, London, Pitman.

Welsh, J. A. \& White. J. F. (1981). A Small Business is not a Big Business. Harvard Business Review, 59(4), 1832.

Williams, H., Van-Hooydonk, A., Dingle, P. \& Annandale, D. (2000). Developing tailored environmental management systems for small business. Eco - Management and Auditing, 7, 106-113. 